\title{
Energy consumption, economic development and prices: Time series evidence in CESEE countries
}

\author{
Dushko Josheski, Marija Magdinceva-Sopova, Zlatko Sovreski \\ University Goce Delcev-Stip
}

\begin{abstract}
This paper estimates the causal relationships between energy consumption and income for Albania, Bosnia and Herzegovina, Serbia, and Macedonia (CESEE - Central, Eastern and Southeastern Europe countries), using cointegration and error-correction modelling techniques. The results indicate that energy consumption, income and prices are second order cointegrated, except for Albania where there exist only one cointegration relationship. In the error correction mechanism on the long run the results show that for the selected countries in the cointegration relationship only inflation does seems to enter significantly in the equation. On a short run also only inflation seems to affect energy consumption, while energy consumption seems to affect income on short run, but only in Albania. This study supports the view that energy and income are neutral. This means that in these countries there is scope for energy conservation measures without severe impact on their economic growth.
\end{abstract}

Keywords: energy consumption, income, prices

\section{Introduction}

In the previous two decades the association between energy consumption and economic growth, with either income or employment as proxy for the latter. Empirical findings had been conflicting and confusing. Seminal article was written by Kraft and Kraft (1978) ${ }^{1}$. These two authors found out evidence on the causality running from GDP to energy consumption, this finding was for United States data. Later, Akarca and Long (1979), were supportive of the Kraft and Kraft study, when they found evidence of the association between employment and energy consumption. But, Yu and Choi $(1985)^{2}$, and previously Yu and Hwang (1984) ${ }^{3}$, found no causal relationship between income and energy consumption. Reason, why there was such a inconsistency in the results was because earlier studies employed OLS, not taking into account different nature of times series, and previously was not known that in levels series are not stationary, Granger, Newbold(1974) $)^{4}$.Regressions with high value fo fit as measured by $\mathrm{R}^{2}$ and low measure of Durbin-Watson statistic. Low Durbin statistics means autocorrelation, in her presence error are autocorelated.

\footnotetext{
${ }^{1}$ Kraft, J., Kraft, A., (1978). On the relationship between energy and GNP. J. Energy Dev. 3, 401-403.

$2 \mathrm{Yu}$, E.S.H., Choi, J.Y., 1985. The causal relationship between energy and GNP: an international comparison. J. Energy Dev. 10, 249]272

${ }^{3}$ Yu, E.S.H., Hwang, B.K., (1984). The relationship between energy and GNP: further results. Energy Econ. 6, 186-190

${ }^{4}$ Granger, C., Newbold, P., (1974). Spurious regressions in econometrics. J. Econometrics 2, 111]120
} 


\section{Methodology and data}

In this paper we are testing the association between income and energy consumption, also in the model inflation is present. The modeling strategy that was adopted, is based on widely used Granger methodology, Engle,Granger $(1981)^{5}$.Though Johansen test ${ }^{6}$ was adopted later because it allows for more than one cointegrating relationship. But first we sue the simplest approach to test for a unit root and that is AR(1) model :

$$
Y_{t}=\theta_{0}+\phi Y_{t-1}+\varepsilon_{t}
$$

On the previous expression residuals follow normal distribution, i.e. $\varepsilon \sim\left(0, \sigma_{a}^{2}\right)$. The null hypothesis that we are testing is:

$$
\begin{aligned}
& H_{0}:|\phi|=1 \Rightarrow Y_{t} \sim I(1) \\
& H_{1}:|\phi|<1 \Rightarrow Y_{t} \sim I(0)
\end{aligned}
$$

Now one to simplify the computation:

$$
\begin{aligned}
& Y_{t}-Y_{t-1}=\theta_{0}-\underbrace{(1-\phi)}_{\delta} Y_{t-1}+a_{t} \\
& \Delta Y_{t}=\theta_{0}-\delta Y_{t-1}+a_{t}
\end{aligned}
$$

And, if $\delta=0$, system has a unit root.

$$
\begin{aligned}
& H_{0}: \delta=0 \\
& H_{1}: \delta<0
\end{aligned}
$$

In the second part of the empirical chapter one can use Johansen procedure fopr testing of the cointegration rank between the variables. This approach is similar to augmented DickeyFuller test but it requires for VAR approach.

\footnotetext{
5 Granger, Clive (1981). "Some Properties of Time Series Data and Their Use in Econometric Model Specification". Journal of Econometrics 16 (1): 121-130.

${ }^{6}$ Johansen, Soren (1991). "Estimation and Hypothesis Testing of Cointegration Vectors in Gaussian Vector Autoregressive Models". Econometrica 59 (6): 1551-1580. JSTOR 2938278.
} 
$x_{t}=A_{1} x_{t-1}+\varepsilon_{t}$

$\Delta x_{t}=\left(A_{1}-\right.$ IDmatrix $) x_{t-1}+\varepsilon_{t}$

$\Delta x_{t}=v x_{t-1}+\varepsilon_{t}$

where $v=A_{1}-$ IDmatrix

So in Johansen cointegrating relationship IDmatrix is identity matrix, $A_{1}$ is a ${ }^{\times} \mathrm{g}$ matrix, $\mathrm{x}_{\mathrm{t}}$ and $y_{t}$ are cointegratinge vectors. The rank of $\mathrm{v}$ is the number of cointegrating relationships. After one determines the number of cointegrating relationships, one can use VECM model to capture the long run relationship between variables in the model.Vector Error Correction Models (VECM) are the basic VAR, with an error correction term incorporated into the model and as with bivariate cointegration, multivariate cointegration implies an appropriate VECM can be formed. We are estimating the error correction mechanism by using the lagged residuals $\mathrm{u}_{\mathrm{t}-1}$.

$$
\Delta \mathrm{Y}_{\mathrm{t}}=\beta_{0}+\beta_{1} \Delta X_{t}-\beta_{2}\left(Y_{t-1}-C-\beta X_{t-1}\right)
$$

Now the error correction mechanism is :

$$
E C=\left(Y_{t-1}-C-\beta X_{t-1}\right)
$$

In the cointegrating regression

$$
\begin{aligned}
& Y_{t}=C+X_{t}+u_{t} \\
& u_{t}=Y_{t}-C-X_{t}==>u_{t-1}=Y_{t-1}-C-\beta X_{t-1}
\end{aligned}
$$

$\mathrm{u}_{\mathrm{t}-1}$ in the last expression represents error correction mechanism. Data used in this paper are gathered from World Bank and World development indicators published by the World Bank. The precise definitions of the variables are as follows:

LogGDP-logarithm of GDP in current US dollars.

Logenergyuse-logarithm of Energy use ( $\mathrm{kg}$ of oil equivalent per capita)

LogCPI-Logarithm of inflation, consumer prices annual percentage

Here we set the hypothesis that energy efficiency measures in the countries of the sample will not deteriorate growth. 


\section{Energy sectors and energy efficiency measures in selected CESEE economies}

Energy efficiency represents the using of less quantities of energy for executing the same activity or function as such heating to a certain area, lighting, the production of other elements, cooling to a certain area, etc. Energy efficiency is not the same as the saving of energy. Energy efficiency is related to the efficient use of energy and the saving of energy the usual is related with waiver of certain executing or spending. Energy efficiency is an important element in energy policy in each national economy because a efficient use of energy is aimed at reducing the consumption for produce the same quantities a certain products or service that the other side contributes to the reduction of financial expenses. Each country implements strategies for energy efficiency, but also leads to policy and implementation of directives for energy efficiency. Measures that are necessary for the implementation the policy on energy efficiency in the Republic of Serbia represent the adoption of the necessary legislation for the efficient use of energy, the implementation of a system for managing energy, introduction of subsidies and rebates for the implementation of projects for energy efficiency and increase in public awareness among the population of the importance and efficiency using of energy. The same is imposes itself as a necessity in the Republic of Macedonia, because statistical data show that the use of energy in the Republic of Macedonia has an impact on the environment as a result of the pollution of fuel, cutting in the forest, land degradation, health problems and low energy efficiency. The energy sector in the Republic of Macedonia depends of the import of oil. Every penny intended for the payment of the import of the energy is lost a penny to the national economy. According to the published statistical data, the highest consumer of the geothermal energy in 2010 is the agricultural sector which participates with $83.4 \%$ in the consumption and other sectors participate with $16.6 \%$ in the consumption and losses in the distribution of energy equalling $10.45 \%$. Therefore the increase in energy efficiency and the achievement of sustainable development should be made through implementation of the system and projects in which priority will have total consumption, distribution and providing of energy. The energy sector in Bosnia and Herzegovina represents one of the most important part of the economy. Bosnia and Herzegovina has important hydropower potential that is used about $40 \%$, and oil and gas imported. The energy intensity of the economy is expected to be 2.5 times higher than the EU average as an indicator of the high potential for improving the energy efficiency. In Bosnia and Herzegovina in progress is a process of adaptation of the energy system to the international standards and best practices of the European Union. In Albania, the energy 
sector is also one of the most important sectors. Energy sources basically are based on hydro energy, which represents the primary source of energy and the demand for energy is characterized by a tendency to increase. Satisfying the energy needs of Albania is projected to be realized through the improvement of control an increase in the consumption, reducing the energy dependency and interventions for improve the energy efficiency.

\section{Empirical section results}

In this part first the results from the Dickey-Fuller test are being presented in Table 1.

Table 1 Results from the empirical testing Dickey -Fuller test

\begin{tabular}{|c|c|c|}
\hline Country/variable & Levels & First difference \\
\hline \multicolumn{3}{|c|}{ Albania } \\
\hline LogGDP & -0.424 & -4.425 \\
\hline Log energyuse & -1.580 & -4.126 \\
\hline $\log C P I$ & -2.910 & -4.400 \\
\hline \multicolumn{3}{|c|}{ Bosnia and Herzegovina } \\
\hline LogGDP & -2.288 & -4.629 \\
\hline Log energyuse & 0.989 & -0.989 \\
\hline $\log C P I$ & -1.557 & -5.908 \\
\hline \multicolumn{3}{|c|}{ Macedonia } \\
\hline LogGDP & -0.494 & -4.035 \\
\hline Log energyuse & -3.227 & -3.227 \\
\hline $\log C P I$ & -3.004 & -6.986 \\
\hline \multicolumn{3}{|c|}{ Serbia } \\
\hline LogGDP & -1.522 & -4.816 \\
\hline Log energyuse & -2.817 & -2.817 \\
\hline $\log \mathrm{CPI}$ & -1.751 & -5.084 \\
\hline \multicolumn{3}{|c|}{ Critical values } \\
\hline $10 \%$ & -3.750 & -3.730 \\
\hline $5 \%$ & -3.000 & -2.999 \\
\hline $1 \%$ & -2.630 & -2.630 \\
\hline
\end{tabular}

From the previous Table 1 one can see that all variables contain unit root when in levels, but when first differenced all are stationary. Now, since all variables are I(1), ie.e integrated of order one, one can check whether they are cointegrated.Cointegration tests are performed 
with all three variables in the model, $\log$ GDP, logcpi, and logenergy use. Johansen maximum likelihood test has been put in use here.

Table 3 Results from Johansen Maximum likelihood test

\begin{tabular}{|c|c|c|c|}
\hline $\begin{array}{l}\text { Country/null } \\
\text { hypothesis }\end{array}$ & eingevalue & SBIC & HQIC \\
\hline \multicolumn{4}{|c|}{ Albania } \\
\hline $\mathrm{r}=0$ & & 2.258129 & 2.14727 \\
\hline $\mathrm{r}=1$ & 0.73001 & $1.630374^{*}$ & $1.334749 *$ \\
\hline $\mathrm{r}=2$ & 0.23371 & 1.773157 & 1.366673 \\
\hline \multicolumn{4}{|c|}{ Bosnia and Herzegovina } \\
\hline $\mathrm{r}=0$ & & 8.711394 & 8.600535 \\
\hline $\mathrm{r}=1$ & 0.62871 & 8.402257 & 8.106632 \\
\hline $\mathrm{r}=2$ & 0.34679 & $8.385375^{*}$ & $7.978892 *$ \\
\hline \multicolumn{4}{|c|}{ SERBIA } \\
\hline $\mathrm{r}=0$ & & 6.708554 & 6.597694 \\
\hline $\mathrm{r}=1$ & 0.59 & 6.4749 & 6.179276 \\
\hline $\mathrm{r}=2$ & 0.42 & $6.336627^{*}$ & $5.930143^{*}$ \\
\hline \multicolumn{4}{|c|}{ Macedonia } \\
\hline $\mathrm{r}=0$ & & 2.72616 & 2.615301 \\
\hline $\mathrm{r}=1$ & 0.46826 & 2.77619 & 2.480565 \\
\hline $\mathrm{r}=2$ & 0.40176 & $2.671407^{*}$ & $2.264924 *$ \\
\hline
\end{tabular}

Note:* denotes statistical significance of the criteria.in this paper as more reliable HannanQuinn and Schwarz Bayesian criterion had been used.

From the Johansen text for cointegration rank one can see that except for Albania, where there exist one cointegrationn equation for the variables of interest, in all other countries there exist two cointegration relationships. This means that for Bosnia, Macedonia and Serbia we will estimate two cointegration equations in the error correction mechanism. And in Albania only one equation. 


\section{VECM models}

Next, we present the results from the Vector error correction mechanism. First for Albania there exist one cointegrating relationship.

\section{Albania -One cointegrating equation}

$$
e c_{t}^{f g l s}=\log \text { energyuse }-\underset{(0.145)}{0.0729 \log G D P}+\underset{(0.000)}{0.3024 \log C P I-5.063972}
$$

If one rearranges the last expression for logarithm of energy use can get :

$$
\text { logenergyuse }=\underset{(0.145)}{5.063972}+\underset{(0.000)}{0.0729} \log G D P \underset{t}{0.3024 \log C P I+e c_{t}^{f g l s}}
$$

From the above equation one can see that if inflation increases by $1 \%$, energy consumption will fall by $0.3 \%$,coefficient on GDP is positive but insignificant at long run.

\section{Bosnia and Herzegovina -2 cointegrating equations}

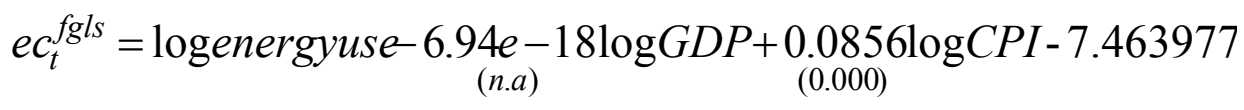

If one rearranges the last expression for logarithm of energy use can get :

$$
\log \text { energyuse }=\underset{(\text { n.a })}{6.94 e-18 \log G D P} \underset{(0.000)}{0.0856 \log C P I+e c_{t}^{f g l s}}+7.463977
$$

Second cointegrating equation for Bosnia and Herzegovina:

$$
e c_{t}^{f g l s}=\log G D P+\underset{(0.073)}{0.5497 \log C P I-26.60594}
$$

In the last equation energy use variable had been omitted.

$$
\log G D P=26.60594-\underset{(0.073)}{0.5497 \log C P I+e c_{t}^{f g l s}}
$$

In Bosnia there existed two cointegrating relationships, sign on inflation in relation to energy consumption is negative and significant, and the coefficient on GDP when in relation to log of energy use is insignificant, this is for the first equation. And, for the second equation, when $\log$ GDP is dependent variable, logCPI is negative and significant and energy consumption variable is omitted from the regression.

\section{Macedonia -2 cointegrating equations}

$$
e c_{t}^{f g l s}=\underset{(\text { n.a })}{\operatorname{logenergyuse}} \underset{(0.004)}{1.39 E-17 \log G D P}+\underset{0}{0.123 \log C P I-7.4279}
$$


If one rearranges the last expression for logarithm of energy use can get :

$$
\log \text { energyuse }=7.42799+\underset{(\text { n.a })}{1.39 E_{(0.004)}}-17 \log G D P-\underset{\left(0.1231 \log C P I+e c_{t}^{f g l s}\right.}{0.10}
$$

Second cointegrating equation for Macedonia is:

$$
e c_{t}^{f g l s}=\log G D P+\underset{(\text { n.a. })}{7.11} \underset{1}{e-15 \log e n e r g y u s e}+\underset{(0.004)}{1.637 \log C P I-25.47}
$$

In the last equation energy use variable had been omitted.

$$
\log G D P=25.47-7.1{\underset{(\text { n.a. })}{e}-15 \log \text { energyuse }}_{(0.004)}^{1.637} \log C P I+e c_{t}^{f g l s}
$$

As for Macedonia there also existed two cointegrating equations. Log GDP is positively associated with the energy consumption but the coefficient is insignificant.Inflation in the two equations is negatively and statistically significantly associated with the energy consumption and GDP.

\section{Serbia -2 cointegrating equations}

$$
e c_{t}^{f g l s}=\log \text { energyuse }+\underset{(0.000)}{0.0349418 \log C P I-7 . .88}
$$

In the previous expression log of GDP is omitted,If one rearranges the last expression for logarithm of energy use can get :

$$
\log \text { energyuse }=7.88-\underset{(0.000)}{0.0349418} \log C P I+e c_{t}^{f g l s}
$$

Second cointegrating equation for Macedonia is:

$$
e c_{t}^{f g l s}=\log G D P+\underset{(0.000)}{2.07} \log C P I-29.30
$$

In the last equation energy use variable had been omitted.

$$
\log G D P=29.30-\underset{(0.000)}{2.07} \log C P I+e c_{t}^{f g l s}
$$

As for Macedonia there also existed two cointegrating equations. Log GDP is omitted when energy consumption is dependent variable. Also energy consumption is omitted from the model when log GDP is dependent variable. Inflation in the two equations is negatively and statistically significantly associated with the energy consumption and GDP. 


\section{Conclusion}

The purpose of this paper was to test the association and causality between income (GDP), energy consumption (use of oil $\mathrm{kg} /$ per capita), and prices represented through inflation. Maximum likelihood procedures were used one to analyses time series properties of the variables, and error correction models in order to see the long run relationship between the variables. From the results one can see that in Albania there exists one directional causality from prices to energy consumption. In Bosnia and Herzegovina there exist two one way relationships between inflation and energy consumption, and prices and income (i.e. GDP).In Macedonia. In Macedonia there exists two way association between energy consumption and GDP, but the statistical significance of that causality is unknown. Also, in Macedonia there exist two one way relationships between inflation and energy consumption, and prices and income (i.e. GDP).Price effects are very significant in the causality equations. Our results suggest that in some cases, energy consumption, income and price are endogenous and therefore single equation forecasts of one or the other could be misleading. This notion is the same as in the study of Adyaye (2000) $)^{7}$.This means that in these countries there is scope for energy conservation measures without severe impact on their economic growth.

\footnotetext{
${ }^{7}$ Adjaye,J.A.,(2000), The relationship between energy consumption, energy prices and economic growth: time series evidence from Asian developing countries, Energy Economics 22 2000. 615-625,Elsevier.
} 


\section{References}

[1].Adjaye,J.A.,(2000), The relationship between energy consumption, energy prices and economic growth: time series evidence from Asian developing countries, Energy Economics 22 2000. 615-625,Elsevier.

[2]. Granger, C., Newbold, P., (1974). Spurious regressions in econometrics. J. Econometrics 2, 111]120

[3]. Granger, Clive (1981). "Some Properties of Time Series Data and Their Use in Econometric Model Specification". Journal of Econometrics 16 (1): 121-130.

[4]. Johansen, Soren (1991). "Estimation and Hypothesis Testing of Cointegration Vectors in Gaussian Vector Autoregressive Models". Econometrica 59 (6): 15511580. JSTOR 2938278.

[5].Kraft, J., Kraft, A., (1978). On the relationship between energy and GNP. J. Energy Dev. 3, 401-403.

[6].Yu, E.S.H., Choi, J.Y., 1985. The causal relationship between energy and GNP: an international comparison. J. Energy Dev. 10, 249]272

[7].Yu, E.S.H., Hwang, B.K., (1984). The relationship between energy and GNP: further results. Energy Econ. 6. 